\title{
ATTRACTANT PHEROMONE FOR NEARCTIC STINK BUG, Euschistus obscurus (HETEROPTERA: PENTATOMIDAE): INSIGHT INTO A NEOTROPICAL RELATIVE ${ }^{1}$
}

\author{
MIGUEL BORGES ${ }^{2,3, *}$ and JEFFREY R. ALDRICH ${ }^{4}$ \\ ${ }^{2}$ EMBRAPA/CENARGEN/ACB-Cx. Postal: 02372, Cep.: 70849-970, Brasilia-DF-Brazil. \\ ${ }^{4}$ USDA-ARS, Insect Chemical Ecology Laboratory, Beltsville, Maryland 20705.
}

(Received June 10, 1993; accepted October 22, 1993)

\begin{abstract}
Volatiles from Euschistus obscurus males were found to be attractive to conspecific females in bioassays. A new type of olfactometer assembled from commercially available glassware was used to bioassay aeration extracts of the Nearctic stink bug, E. obscurus. Fractionated extracts suggest that pheromonal activity is associated with late-eluting, male-specific compounds. Research on $E$. obscurus offered a means to indirectly study the pheromone of the Neotropical pest species, $E$. heros, without importing this soybean pest into the United States.
\end{abstract}

Key Words-Euschistus heros, behavior, olfactometer, attraction, volatiles.

\section{INTRODUCTION}

Soybean, Glycine $\max$ (L.) Merril, in the United States and around the world is damaged by complexes of stink bugs. In the United States, the most important members of the complex are Nezara viridula (L.), Acrosternum hilare (Say), Euschistus servus (Say), and other Euschistus spp. (Turnipseed, 1973; Russin et al., 1987). Several species of Euschistus have been reported as sporadic pests of deciduous fruits, cotton, and seed alfalfa (Borden et al., 1952; Hoffmann et al., 1987; Toscano and Stem, 1976). In Central and South America, other

* To whom correspondence should be addressed.

'Research performed as a Visiting Scientist at: USDA-ARS, Insect Chemical Ecology Laboratory, Beltsville, Maryland 20705. Mention of commercial products does not constitute an endorsement by the U.S. Department of Agriculture.

${ }^{3}$ Supported by a grant from $\mathrm{CNPq}$. 
Euschistus spp. are important pests (Panizzi and Slansky, 1985). For example, the Neotropical pentatomid, E. heros $\left(\mathrm{F}_{\text {. }}\right.$, is a major pest of soybean in Brazil (Panizzi and Rossi, 1991).

A chemical attractant for Euschistus species would be a valuable means to monitor levels of these pests (Aldrich et al., 1991). In addition, attractants might be useful for concentrating the stink bugs in early maturing trap crops where they could be economically destroyed by limited insecticide application (McPherson and Newson, 1984). The identification and attractiveness of a major pheromone component for Nearctic Euschistus spp. was reported by Aldrich et al. (1991). Methyl $(2 E, 4 Z)$-decadienoate is the major male-specific volatile of five Euschistus spp. In an analysis of a single individual for a sixth species, $E$. obscurus (Palisot), this ester was a relatively minor male-specific component, with the major component being tentatively identified as methyl 2,6-dimethyltetradecanoate (Aldrich et al., 1991). It has now been determined that the putative identification was incorrect (Aldrich et al., 1993). Our aerations of $E$. heros indicate that males of this species may produce the same major pheromone as $E$. obscurus. This study of $E$. obscurus was undertaken primarily as a means to elucidate the chemical communication system of its Neotropical relative, $E$. heros. To do this, a bioassay was developed to quantify female $E$. obscurus responses to the odor of live male $E$. obscurus and to extracts of the pheromone isolated from males.

\section{METHODS AND MATERIALS}

Insects. E. obscurus was obtained from a laboratory colony from Dr. W. Jones (USDA-ARS-SPA, Weslaco, Texas) and reared on sunflower seeds, soybeans, and green beans at $28^{\circ} \mathrm{C}$ and $65 \%$ relative humidity on a $16: 8$-hr lightdark photoperiodic regime. To prevent olfactory interactions between the sexes, males were separated from females after the imaginal molt and cuticular hardening, but before sexual maturity (ca. 48-72 hr).

Volatiles Extracts. Samples were collected from groups of 40 virgin adult male or female $E$. obscurus of known age by coaxing the bugs into a 1-liter glass column and trapping volatiles from the air drawn by vacuum $(100 \mathrm{ml} /$ $\mathrm{min}$ ) over the bugs through $30 \mathrm{mg}$ of activated charcoal for $24 \mathrm{hr}$. Trapped volatiles were washed from the filter in $150 \mu \mathrm{l}$ of $\mathrm{CH}_{2} \mathrm{Cl}_{2}$ and stored at $-20^{\circ} \mathrm{C}$ (Aldrich et al., 1987). Extraction of E. heros, in the Brazilian laboratory, followed the same methodology described for $E$. obscurus.

Fractionated Samples. Fractions were isolated in glass capillary tubes jacketed in Dry Ice as they eluted from a DB-1 column (15 m $\times 0.53 \mathrm{~mm}$ ID) in a Varian $3700 \mathrm{GC}$ equipped with a thermal conductivity detector (Aldrich et al., 1987), isothermally at $150^{\circ} \mathrm{C}$ for $6 \mathrm{~min}$. 
Samples were analyzed by gas chromatography (GC) on a bonded methyl silicone column $(0.25-\mu \mathrm{m}$ film, $30 \mathrm{~m}$ long, $0.25 \mathrm{~mm}$ ID; DB-1, J \& W Scientific, Folsom, California) using a Varian $3500 \mathrm{GC}$ with helium as carrier ( 40 $\mathrm{cm} / \mathrm{sec}$ ), and a temperature program from $50^{\circ} \mathrm{C}$ for $2 \min$ to $235^{\circ} \mathrm{C}$ at $15^{\circ} \mathrm{C} /$ min with a 2 -min final hold.

Olfactometer. A two-choice olfactometer was used to test the biological activity of live males, male aeration extracts, and trapped fractions (Figure 1). The olfactometer consisted of a release chamber that was a 500-ml three-neck, round-bottom flask (all 204/40 joints, Kontes, Vineland, New Jersey 08360$2841)$. Two $250-\mathrm{ml}$ rotary evaporator trap adapters (24/40 joints) were attached to the side arms (the treatment and control chambers). Charcoal filters (20/40 mesh) were attached to the side arms using $24 / 40$ to $14 / 35$ adapters to $130-\mathrm{mm}$ $\times 10-\mathrm{mm}$ ID, charcoal-filled columns. The middle neck of the flask was connected to the house vacuum through an adapter (24/40 to 10/30, reducing/ enlarging joints) adjusted with a valve to a flow of $0.75 \mathrm{ml} / \mathrm{sec}$. The apparatus was positioned horizontally on a countertop in a room $\left(24 \pm 1.5^{\circ} \mathrm{C}\right)$ with bright fluorescent lights (Aldrich et al., 1990).

Bioassay. Observations through the day showed no obvious variation in the level of responsiveness of females to males. The bioassays were therefore run throughout the light period between 9:00 AM and 4:00 PM and were allowed to run for $\mathbf{2 0} \mathrm{min}$ for all computed data.

The bioassay procedure used by Borges et al. (1987) was followed with some modification as follows: the natural stimulus was provided by two sexually mature virgin males ( $>14$ days old), released into the treatment chamber, and

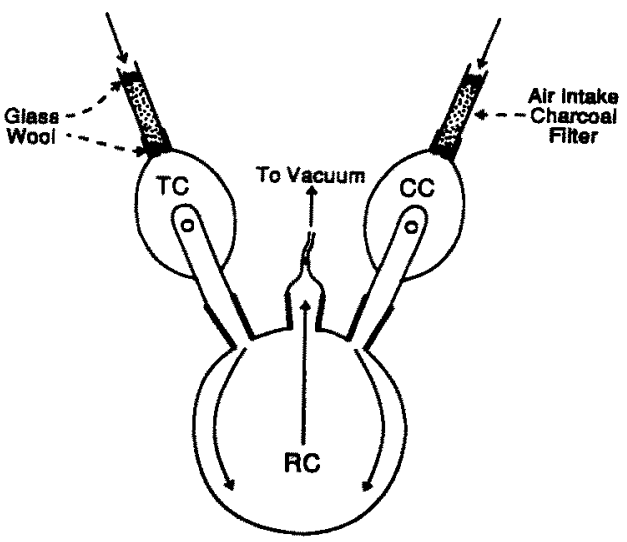

FIG. 1. Olfactometer apparatus used in the bioassays. $\mathrm{TC}=$ treatment chamber, $\mathrm{CC}=$ control chamber, $\mathrm{RC}=$ release chamber. Air moves from the treatment/control chamber to the release chamber (arrows). Dimensions quoted in text. 
10 sexually mature females were placed into the release chamber. Prior to testing, the insects were allowed to acclimatize for a short period (ca. $5 \mathrm{~min}$ ) in the release chamber before attaching the side arms. The olfactometer sections were then connected, and the behavioral responses of females were recorded. Females that entered a ball of a rotary evaporator trap were counted as making a choice; data are reported as percent response. Sixteen replicates were performed using 10 females per replicate and blank as a control.

Effects of male aeration extracts on the behavioral responses of females was determined by recording female responses to $0.3,1.3$, and 2.7 individual equivalents (IE) applied to a strip of filter paper $(2.0 \times 0.5 \mathrm{~cm})$ with 1,5 , or $10 \mu \mathrm{l}$ microcap (Dnummond), respectively (1 $\mathrm{IE}=3.75 \mu \mathrm{l}$ of extract). The solvent was allowed to evaporate for $20 \mathrm{sec}$ and then the filter paper strips were placed in the ball of the rotary evaporator trap for the treatment side of the olfactometer. As a control, the same dose of solvent on a filter paper strip was placed in the control chamber, allowed to evaporate, and the filter paper was tested simultaneously with the male aeration extract. Sixteen replicates were performed using 10 females per replicate.

Effects of the fractionated male aeration extract on the behavioral responses of females were determined by recording female responses to a series of trapped fractions. The first "fraction" assayed, the total fraction, was a 6-min elution to monitor activity of all volatiles submitted to the GC program. Fraction 1 was the trapped fraction eluting from injection until $2.5 \mathrm{~min}$, and fraction 2 consisted of the trapped volatiles from 2.5 to $6.0 \mathrm{~min}$. The bioassay of the trapped fractions followed the same methods as for male aeration extracts. Four replicates were performed using 10 females per replicate and solvent as a control.

Statistical Analysis. Statistical analyses were performed on a microcomputer using StatXact-Turbo, statistical software for exact nonparametric inference (CYTEL software Corp., Cambridge, Massachusetts 02139). Each control versus treatment combination was analyzed as a paired difference using the Wilcoxon signed rank test. The difference was treatment minus control for each replicate. The $P$ values for the alternate hypothesis (Ha: the difference between the treatment and control is not zero) are reported on the figures.

\section{RESULTS}

GC analysis showed that the $E$. obscurus male aeration extracts contained a high concentration of two volatile compounds and relatively low concentrations of others (Figure 2). Chemical analysis disclosed that three of the volatiles of $E$. obscurus also are released by $E$. heros males (Figure 2) (Aldrich et al., 1993 ). For both $E$. obscurus and $E$. heros, aeration extracts of females totally lacked compounds 1,2 , and 3 . 


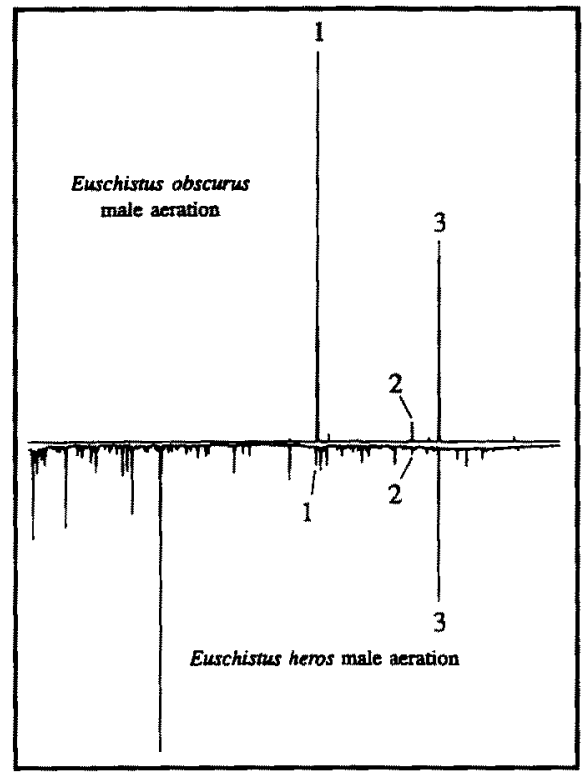

FIG. 2. Gas chromatograms from 40 male Euschistus obscurus and 40 male Euschistus heros. Numbers indicate matching compounds verified by GC-MS (Aldrich et al., 1993).

There was no significant attraction of sexes to extracts of the same sex; i.e., female insects were not attracted to extracts of females, and male insects were not attracted to extracts of males. Although live females were not tested, there was no significant difference in the attraction of males to extracts of females as compared to controls (Figure 3). However, it was observed that males always showed a higher upwind response than females. On the other hand, the attraction of females to live males and extracts of live males at 0.3 and $1.3 \mathrm{IE}$ was significantly greater than controls. At higher concentrations ( $2.7 \mathrm{IE})$ the attraction of females to extracts of males was not significantly different from controls (Figure 4).

Results of bioassays for fractions were not significant at the $95 \%$ level. Responses to the total fraction $(P=0.25)$ and fraction $2(P=0.125)$ were comparable, whereas response to fraction 1 was low $(P=0.75)$.

\section{DISCUSSION}

The major male-specific compound of $E$. heros (ignoring chirality) is also abundantly produced by $E$. obscurus males (Aldrich et al., 1993). Thus, studying the Nearctic $E$. obscurus offered a means to identify and study the pheromone 


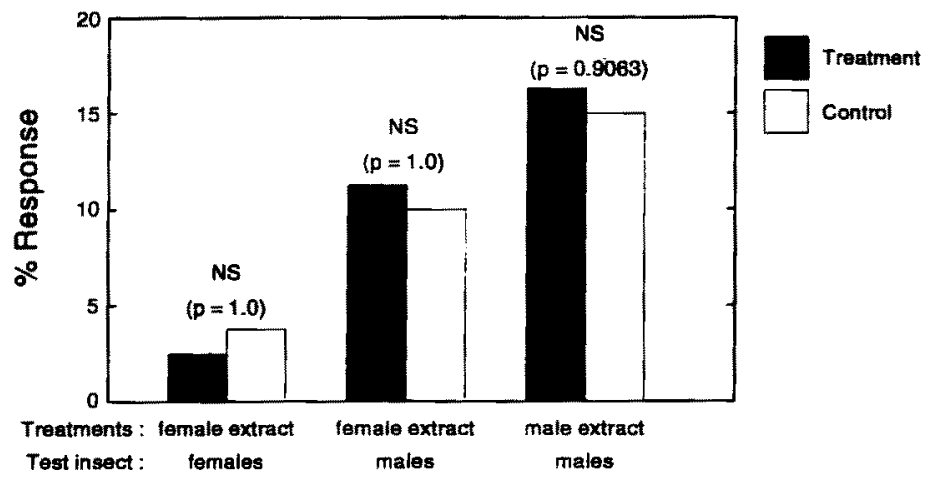

FIg. 3. Percentages of females responding to $1.3 \mathrm{IE}$ dose of female aeration extract and males responding to $1.3 \mathrm{IE}$ dose of female aeration extract and $1.3 \mathrm{IE}$ dose of male aeration extract.

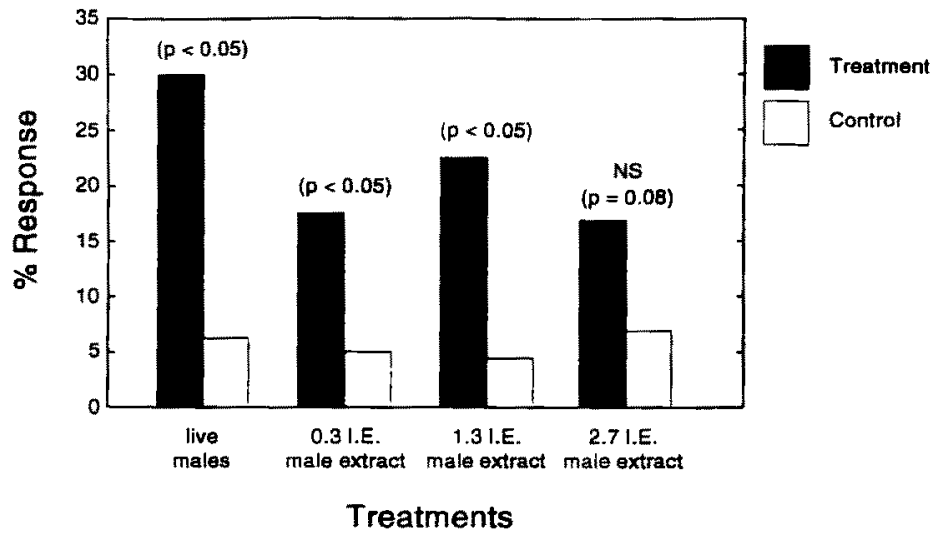

FIG. 4. Percentages of females responding to live males and to $0.3,1.3$, and $2.7 \mathrm{IE}$ of male pheromone extract applied to a filter paper.

of the important Neotropical pest, $E$. heros, without actually importing this pest species into the United States. Moreover, $E$. obscurus males produce about 10 times more pheromone per day than do $E$. heros males, making isolation of sufficient pheromone for analysis more practical.

Euschistus obscurus males release an attractant pheromone, and aeration extracts of males at 0.3 and $1.3 \mathrm{IE}$ were as active as live males in laboratory bioassay. At the higher pheromone concentration tested (2.7 IE) attraction was reduced. Although bioassay results for fractionated pheromone samples were 
not significant at the $95 \%$ level, the high activity of fraction 2 suggests that the main pheromone activity is associated with late eluting compounds.

The higher upwind responses shown by $E$. obscurus males during this study may be a function of the recolonization process characteristic of many heteropteran species. For example, males $P$. maculiventris often search for food first, and then call females with pheromone (Aldrich et al., 1984). This behavior might be related to the periodic migration of the adults of many heteropterans (e.g., Evans, 1982).

A global mapping of the sex pheromones for complexes of economically important pentatomids would be useful for biological control and integrated pest management programs. Many tachinid flies use heteropteran pheromones as host-finding kairomones (Aldrich, 1988) and are important biocontrol agents (Todd, 1989). If tachinids discriminate between host pheromone blends, it is important that these parasites be imported from regions where the host has a compatible pheromone blend.

Further chemical and behavioral research must be carried out in Brazil for $E$. heros, including testing individual stereoisomers that are now being synthesized (K. Mori, personal communication).

Acknowledgments-We are grateful to EMBRAPA/CENARGEN, CNPq, and to the U.S. Department of Agriculture for their financial support of the first author during his stay in the United States. We would like to thank Mr. Kenneth R. Wilzer Jr., USDA-ARS-INHL Beltsville, for his help with the computer, Dr. Mary Camp for her help with the statistical analysis.

\section{REFERENCES}

ALDRICH, I.R. 1988. Chemical ecology of the Heteroptera. Annu. Rev. Entomol. 33:211-238.

ALDRich, J.R., KOCHANSKY, J.P., and ABRAMS, C.B. 1984. Attractant for a beneficial insect and its parasitoids: Pheromone of the spined soldier bug, Podisus maculiventris (Hemiptera: Pentatomidae). Environ. Entomol. 13:1031-1036.

ALDRICH, J.R., Ouiver, J.E., LUSBY, W.R., KoChANSKY, J.P., and LOCKwOOd, J.A. 1987. Pheromone strains of the cosmopolitan pest, Nezara viridula (Heteroptera: Pentatomidae). J. Exp. Zool. 244:171-175.

AldRich, J.R., Carrol, S.P., Lusby, W.R., Thompson, M.J., Kochansky, J.P., and Waters, R.M. 1990. Sapindaceae, cyanolipids, and bugs. J. Chem. Ecol. 16:199-210.

Aldrich, J.R., Hoffmann, M.P., Kochansky, J.P., LuSBY, W.R., Eger, J.E., and PAYNE, J.A. 1991. Identification and attractiveness of a major pheromone component for Nearctic Euschistus spp. stink bugs (Heteroptera: Pentatomidae). Envirom. Entomol. 20:477-483.

AlDRICH, J.R., OLIVER, J.E., LuSBY, W.R., KochansKY, J.P., and BoRGES, M. 1993. Chemistry of male-specific volatiles from Nearctic and Neotropical stink bugs (Heteroptera: Pentatomidae). J. Chem. Ecol. Submitted.

Borden, A.D., MADSEN, H.F., and Retan, A.H. 1952. A stink bug, Euschistus conspersus, destructive to deciduous fruits in California. J. Econ. Entomol. 45:254-257.

BORGES, J., JEPSON, P.C., and HOWSE, P.E. 1987. Long-range mate location and close-range courtship behaviour of the green stink bug, Nezara viridula and its mediation by sex pheromones. Entomol. Exp. Appl. 44:205-212. 
Evans, E.W. 1982. Timing of reproduction by predatory stinkbugs (Hemiptera: Pentatomidae): Patterns and consequences for a generalist and specialist. Ecology 63:147-158.

HofFMANN, M.P., WILSON, L.T, and ZALON, F.G. 1987. Control of stink bugs in tomatoes. Calif, Agric. 41:4-6.

MCPherson, R.M., and NEwson, L.D. 1984. Trap crops for control of stink bugs in soybeans. J. G. Entomol. Soc. 19:470-480.

PANIzZl, A.R., and Rossie, C.E. 1991. The role of Acanthospermum hispidum in the phenology of Euschistus heros and of Nezara viridula. Entomol. Exp. Appl. 59:67-74.

PANIZZ, A.R., and SLANSKY, J., JR. 1985. Review of phytophagous pentatomids (Hemiptera: Pentatomidae) associated with soybean in the Americas. Fla. Entomol. 68:184-214.

Russin, J.S., LAYTON, M.B., ORR, D.B., and BOETHEL, D.J. 1987. Within-plant distribution of, and partial compensation for, stink bug (Heteroptera: Pentatomidae) damage to soybean seeds. I. Econ. Entomol. 80:215-220.

ToDD, J.W. 1989. Ecology and behavior of Nezara viridula. Annu. Rev. Entomol. 34:273-292.

TOSCANo, N.C., and STERN, V.M. 1976. Cotton yield and quality loss caused by various levels of stink bugs infestations. J. Econ. Entomol. 69:53-56.

TURnIPSEed, S.G. 1973. Insects, pp. 545-572, in B.E. Caldwell (ed.). Soybeans: Improvement, Production, and Uses. American Society of Agronomy, Madison, Wisconsin. 